\title{
Students' Reading Proficiency and Academic Performance
}

\author{
Alona Medalia Cadiz-Gabejan ${ }^{1}$ 8(D) $\triangle$ and Madelyn C. Quirino ${ }^{2}$ 8(D) \\ ${ }^{7}$ Assistant Professor II, Samar State University, Catbalogan City, Philippines \\ 2Elementary Grade Teacher III, Department of Education, Catbalogan City, Philippines
}

Corresponding Author: Alona Medalia Cadiz-Gabejan, E-mail: alonamedalia.gabejan@ssu.edu.ph

\author{
ARTICLE INFORMATION \\ Received: May 18, 2021 \\ Accepted: June 17, 2021 \\ Volume: 3 \\ Issue: 6 \\ DOI: 10.32996/ijels.2021.3.6.4
}

\section{KEYWORDS}

Reading proficiency, Reading competence, Academic performance, Academic achievement

\section{ABSTRACT}

Reading proficiency and academic performance are both of paramount importance to a learner's holistic academic success. These aspects of a student's journey must not be taken for granted regardless of their locale, cultural context, and academic setting. Consequently, this intellectual endeavor examined the correlation of said factors. It first probed into the students' profile and determined their reading proficiency level $(R P L)$ and academic performance (AP) in English based on the Phil-IRI result and mean percentage scores. Using descriptive-correlational analysis, the study investigated the significant differences in the RPL of the students when grouped according to their profile variates and the significant relationship between their AP and RPL. Findings revealed that the latter differed in terms of sex, parents' highest educational attainment, parents' occupation, and a number of days of attendance in school, but similar along with age, nutritional status, and attitude toward reading. Students showed a favorable AP in reading as depicted in the positive coefficient result, suggesting a direct proportional linear relationship indicating that students with higher RPL manifested higher AP than those whose reading performance was on the average only. Hence, the study inferred that students need an intervention program for their reading skills and in becoming independent readers. Also, as female students were proven to manifest higher RPL, it was recommended that teachers provide enhancement activities for male students to be at par with their female counterparts. Thus, this empirical information would be beneficial to both schools and educators in strengthening every learner's reading proficiency and academic performance.

\section{Introduction}

It is common knowledge that reading is the process of getting meaning from the printed page. It is the process of interpreting symbols drawn from the author's image, idea, emotion, or experience. According to Leipzig (2001), reading is a multifaceted process involving word recognition, comprehension, fluency, and motivation. Reading is a cognitive process centred in the brain, including the processes that the brain utilizes in mental activities (e.g. paying attention to something, forgetting an important call).

Reading, being a tool subject, is so essential that a teacher must provide all the developmental reading instructions that students need. Koda and Zehler (2008) affirmed that it is a vital component of academic learning that helps the reader be a learned one in the broader community. If a child is deficient in reading, he encounters difficulty in all subject areas. Failure to achieve sufficient proficiency in reading hinders his access to the needed tools for further learning. Thus, a teacher must give special attention to those who have difficulties in reading.

Reading is one of the most complex subjects in the school curriculum. It consists of a combination of general abilities which an expert reader ought to have. Schools today have students whose reading skills need to be developed if they are to achieve better in the different subject areas. A prognosis of the child's ultimate reading level based upon observation and diagnosis is

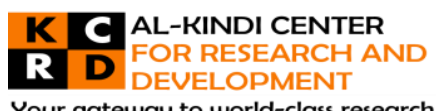

Your gateway to world-class research

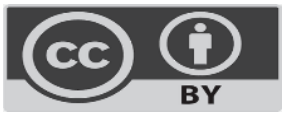

Published by Al-Kindi Center for Research and Development. Copyright (c) the author(s). This open access article is distributed under a Creative Commons Attribution (CC-BY) 4.0 license 
necessary for each child before the appropriate reading program can be designed for them. It is impossible to provide good reading instruction without knowing every child's present level of achievement and to what level he may progress. Therefore, successful teaching in reading should be based on a realistic diagnosis of what the pupils can do now and what they are for the next (The National Academies Press, 2010).

Apparently, previous analysis of the achievement of public elementary students in the country came up with a saddening conclusion: their performance and achievement in reading were three grades below their grade level (Aquino, 2000). Even in the 2018 Program for International Student Assessment (PISA), results showed that the Philippines ranked 79th in reading, with an average of 340 against the OECD average of 487 (PISA, 2018). Accordingly, this clearly indicated the seriousness of the problem confronting the teacher and school officials who fear the growing, inadequate, and substandard quality of Philippine Education at the elementary level. Several measures and programs of the Department of Education (DepEd) were implemented to address such a problem; however, year in and year out, the same problem was still encountered. This was shown by the reading level of the elementary grade students in the Phil-IRI results, whereby 60.77 percent are in the frustration level.

Likewise, it is a common practice in the District of Catbalogan VI to test the students to identify their reading levels and plan classroom instruction and teaching techniques. This is an Oral Reading Proficiency Test (ORPT) that points out the particular oral reading difficulty that most students are deficient in. It is appalling and disturbing to discover that there are many students who are still very slow in word recognition, more so in answering comprehension questions after reading a text orally.

Another empirical observation that the researcher noted is that the performance of the schools in the Schools Division of Catbalogan City in the National Achievement Tests (NAT), specifically in English, is far below the targeted mastery level of 85 percent. While this is a result of the written tests, it is an indication of the students' low performance which shows some congruence with the results in oral reading tests.

Generally, children's academic performance in public schools was found to be weak to withstand the challenges in the 21st century (Cabardo, 2008). Secretary Andrew Gonzales, former DepEd Secretary, admitted during the Education Congress at Teacher's Camp, Baguio City that poor academic achievement was clearly shown in the low ratings they received in the National Achievement Test (NAT) which were administered by the National Education Testing and Research Center (NETRC). Moreover, the results showed that most of the takers, both in elementary and high school, were weak in the reading comprehension part in English. This denotes that learners had low reading proficiency.

In the classroom setting, most of the pupils who are good at oral communication are mostly performing well in their academics. However, it should be noted that communication is just a part of the learners' total abilities to be developed.

One major cause of the low performance of students in the different assessment tests is the teachers' capability to handle the instructional management aspect of the English instruction (Aquino, 2000:28). It includes the use of various techniques and strategies to teach the different reading skills and appropriate instructional materials to go with these techniques. Verily, English teachers deplore the dearth of teaching materials that complement the suggested materials in the textbook. Notwithstanding the importance of cassette tapes and players which most schools do not have in teaching oral reading skills, several kinds of other materials are wanting. Existing materials like drill cards, flashcards, and charts have been utilized to develop oral reading skills, yet, there is still a need to evolve a particular set of materials that could develop further these skills of Grade 3 students.

From the foregoing situations, the researcher was motivated to conduct this study in order to determine the reading proficiency of the Grade 3 students in the District of Catbalogan VI, Schools Division of Catbalogan City, and its influence on their academic performance during the School Year 2019-2020.

Specifically, it sought to answer the following questions:

1. What is the profile of the student-respondents in terms of the following variates:

1.1 age and sex;

1.2 nutritional status;

1.3 parents' highest educational attainment;

1.4 parents' occupation;

1.5 number of days of attendance in school; and

1.6 attitude toward reading?

2. What is the level of reading proficiency of the student-respondents based on the Phil-IRI result?

3. Are there significant differences in the student-respondents' reading proficiency based on the Phil-IRI result when grouped according to their profile variates? 
4. What is the academic performance of the student-respondents in English based on the mean percentage score during the first and second quarters?

5. Is there a significant relationship between the academic performance of the student-respondents in English based on the mean percentage score during the first and second quarters and their reading proficiency based on the Phil-IRI result?

\section{Methodology}

This section presents the methods undertaken in the conduct of the study. Included herein are the following: research design, instrumentation, validation of the instrument, sampling procedure, data gathering procedure, and statistical treatment of data.

\subsection{Research Design}

This study employed the descriptive-correlation research design using the questionnaire as the main instrument of the study. The study described the profile of the student-respondents in terms of their personal variates, namely: age and sex, nutritional status, parents' highest educational attainment, parents' occupation, number of days of attendance in school, and attitude toward reading. Likewise, the level of reading proficiency of the student-respondents based on the Phil-IRI results was also elicited which was compared when grouped according to their profile variates for any significant variations, and the academic performance based on the mean grade during the first and the second quarters.

Moreover, the study was correlational, considering that the academic performance of the student-respondents based on the mean grade during the first and second quarters was associated with the level of reading proficiency of the student-respondents for any significant linear relationship.

\subsection{Instrumentation}

This study utilized the questionnaire and the school forms in collating relevant information exigent to this study.

\subsubsection{Questionnaire}

The questionnaire was a researcher-developed one. Only one set of questionnaire was prepared by the researcher which was intended for the student-respondents. It was composed of two parts. Part I was designed to gather the profile variates of the student-respondents in terms of the following personal characteristics: age and sex, nutritional status, parents' highest educational attainment, parents' occupation, and the number of days of attendance in school. Part II appraised the attitude of the student-respondents toward reading. It contained 10 attitude statements which were agreed or disagreed by the studentrespondents using the Five-point Likert Scale as follows: 5 for Strongly Agree (SA), 4 for Agree (A), 3 for Uncertain (U), 2 for Disagree (D), and 1 for Strongly Disagree (SD).

\subsubsection{School Forms}

The school forms were the source of the academic performance in English of the student-respondents based on the first and second quarters. This was done through document analysis.

\subsection{Validation of Instrument}

The questionnaire, particularly Part II, was also a researcher-developed instrument. Therefore, it was validated through expert validation focusing on the following areas: face, content, construct, pragmatic, and convergent-discriminant validity with consideration of the cognitive and situational perspectives of the respondents. Comments and suggestions for improvement of the questionnaire from the experts were considered in the revision of the questionnaire whereby it was subjected to a Pilot Test in the District of Catbalogan VII by randomly selecting 20 Grade 3 students. This process looked into the wording of questions, physical setting, respondent's mood, nature of interaction and the regression effect of the respondent. In the calculation of the Coefficient of Reliability, the Cronbach's Alpha Analysis was employed.

\subsection{Sampling Procedure}

This study utilized the random sampling method in choosing the student-respondents. That is, a certain percentage of total Grade 3 enrollment of the district was taken and students were identified using the fishbowl method whereby all the name of the students were encoded in a piece of paper, rolled it and placed in a tambiolo, and raffled off vis-à-vis the number of samples calculated. The names picked out from the tambiolo were interviewed to capture the intended information for this particular study.

\subsection{Data Gathering Procedure}

Before the conduct of the study, the researcher sought authorization from the Schools Division Superintendent of Catbalogan City Division for the conduct of the pilot test and the actual study. Likewise, the same authority was sought from the District 
Supervisor of the Districts of Catbalogan VII and VI for proper courtesy. Then, the same permission was also sought from the respective school head of each school to conduct the study involving their Grade 3 students.

The researcher personally collected the information to ensure that the written procedures were strictly followed and quality data were generated. Data generation lasted for about two months, including travel time. After that, manual editing and coding followed to check the consistency of the information in preparation for the data analysis. Machine processing was the next phase through encoding and generating the statistical information in tabular form using available statistical software.

\subsection{Statistical Treatment of Data}

Descriptive statistical tools were employed to give meaning to the data collected: Frequency Count, Percentage, Arithmetic Mean, Standard Deviation, Weighted Mean, One-Way ANOVA, Tukey's Test, Pearson's Product-Moment Coefficient of Correlation, and the Fisher's t-Test.

In all cases in testing the hypotheses, the decision whether the null hypothesis was accepted or rejected, the following decision rule served as a guide: accept the null hypothesis if and when the computed value turned lesser than the critical or tabular value or the $p$-value turned greater than the $\alpha$; on the other hand, reject the null hypothesis if and when the computed value turned equal or greater than the critical or tabular value or the $p$-value turned equal or lesser than the $\alpha$. The testing of hypotheses assumed the level of significance equals $\alpha=0.05$ in a two-tailed test. Available statistical software or packages were utilized for the accuracy and precision in the data processing.

\section{Results and Discussion}

This section presents the findings of this study with the corresponding analysis and interpretation of data.

\subsection{Profile of Student-Respondents}

This part presents the profile of student-respondents in terms of the following variates, namely: age and sex, nutritional status, parents' highest educational attainment, parents' occupation, number of days of attendance in school, and attitude toward reading.

3.1.1. Age and Sex. Table 1 shows the age and sex of student-respondents.

From the table, it can be gleaned that the student-respondents ranged from eight to 12 years old whereby a number of them, that is, 44 or 44.00 percent were aged nine years old while 35 or 35.00 percent were age eight years old and the rest were slimly distributed to the other identified ages to include 13 or 13.00 percent who did not disclose their age.

Table : Age and Sex Distribution of Student-Respondents

\begin{tabular}{|c|c|c|c|c|c|}
\hline \multirow{2}{*}{ Age } & \multicolumn{3}{|c|}{ Sex } & \multirow{2}{*}{ Total } & \multirow{2}{*}{$\%$} \\
\hline & Male & Female & Not Stated & & \\
\hline 12 & 1 & 0 & 0 & 1 & 1.00 \\
\hline 10 & 2 & 5 & 0 & 7 & 7.00 \\
\hline 9 & 22 & 22 & 0 & 44 & 44.00 \\
\hline 8 & 10 & 25 & 0 & 35 & 35.00 \\
\hline Not Stated & 3 & 3 & 7 & 13 & 13.00 \\
\hline Total & 38 & 55 & 7 & 100 & 100.00 \\
\hline$\%$ & 38.00 & 55.00 & 7.00 & 100.00 & \\
\hline Median & & & 9 years old & & \\
\hline AD & & & 1 year & & \\
\hline
\end{tabular}

The median age of the student-respondents was posted at nine years old with an Average Deviation (AD) of one year. The data signified that the student-respondents were on their right age fitted for the grade level they were enrolled in.

Moreover, the majority of the student-respondents belong to the female sex accounting for 55 or 55.00 percent. The male counterpart was composed of 38 or 38.00 percent. The remaining seven or 7.00 percent hastily failed to indicate their sexes.

The foregoing data suggested female dominance among the student-respondents indicating that more of this sex group were in school and participated in the field interview at the time of visit. 
3.1.2. Nutritional Status. Table 2 presents the nutritional status of the student-respondents. Nutritional Status is an indicator of the students' health status, which influences their receptivity with the lessons in school.

Table 2: Nutritional Status of Student-Respondents

\begin{tabular}{|c|c|c|}
\hline Status & $f$ & $\%$ \\
\hline Normal & 71 & 71.00 \\
\hline Wasted & 8 & 8.00 \\
\hline Severely Wasted & 9 & 9.00 \\
\hline Obese & 6 & 6.00 \\
\hline Not Stated & 6 & 6.00 \\
\hline Total & 100 & 100.00 \\
\hline
\end{tabular}

The table shows that the majority of the student-respondents were in normal nutritional status, accounting to 71 or 71.00 percent while nine or 9.00 percent were severely wasted, eight or 8.00 percent were wasted, six or 6.00 percent were obese and the remaining six or 6.00 percent did not state their nutritional status.

The data signified that the student-respondents were in their best health which suggested that they are apt to understand and learn their lessons.

\subsubsection{Parents' Highest Educational Attainment}

Table 3 provides the parents' highest educational attainment of student-respondents.

\section{Table 3: Parents' Highest Educational Attainment of Student-Respondents}

\begin{tabular}{|c|c|c|c|c|}
\hline \multirow{2}{*}{ Educational Level } & \multicolumn{2}{|c|}{ Father } & \multicolumn{2}{|c|}{ Mother } \\
\hline & $\mathbf{f}$ & $\%$ & $f$ & $\%$ \\
\hline Post Graduate & 0 & 0.00 & 1 & 1.00 \\
\hline College Graduate & 23 & 23.00 & 23 & 23.00 \\
\hline College Level & 11 & 11.00 & 10 & 10.00 \\
\hline Technical-Vocational & 0 & 0.00 & 1 & 1.00 \\
\hline High School Graduate & 11 & 11.00 & 13 & 13.00 \\
\hline High School Level & 8 & 8.00 & 10 & 10.00 \\
\hline Elementary Graduate & 14 & 14.00 & 18 & 18.00 \\
\hline Elementary Level & 17 & 17.00 & 10 & 10.00 \\
\hline No Schooling & 2 & 2.00 & 1 & 1.00 \\
\hline Not Stated & 14 & 14.00 & 13 & 13.00 \\
\hline Total & 100 & 100.00 & 100 & 100.00 \\
\hline
\end{tabular}

Said table provides that of the fathers of the student-respondents, a number of them, that is, 23 or 23.00 percent were college graduates while 17 or 17.00 percent reached the elementary level, 14 or 14.00 percent were elementary graduates, 11 or 11.00 percent were college level, another 11 or 11.00 percent were high school graduates and the rest were distributed to the other identified educational levels.

Likewise, Table 3 shows that 23 or 23.00 percent of the student-respondents were college graduates among the mothers. In comparison, 18 or 18.00 percent were elementary graduates, 13 or 13.00 percent were high school graduates, 10 or 10.00 percent reached the college level, another 10 or 10.00 percent reached the high school level, still another 10 or 10.00 reached the elementary level. The rest were distributed to the other identified educational levels.

The foregoing data suggested that the parents of the student-respondents were functional literate. That is, they have the ability to read, write and understand simple messages. This signified that they are apt to receive information disseminated through the tri-media.

3.1.4. Parents' Occupation. Table 4 shows the parents' occupation of student-respondents. It presents that on the part of the fathers of the student-respondents, a number of them, that is, 36 or 36.00 percent were drivers while 19 of them or 19.00 
percent were laborers, and the rest were thinly distributed to the other identified occupations to include the eight or 8.00 percent of the fathers who did not disclose their primary occupations.

The same table shows that among the mothers of the student-respondents, a number of them, that is, 17 or 17.00 percent were sari-sari storeowners while 10 of them or 10.00 percent were labourers and the rest were distributed to the other identified occupations. Included in these mothers, the 26 or 26.00 percent were not engaged in gainful activities as the housekeepers and 28 or 28.00 percent did not disclose their occupations for unknown reasons.

Table 4: Parents' Occupation of Student-Respondents

\begin{tabular}{|c|c|c|c|c|}
\hline \multirow{2}{*}{ Occupation } & \multicolumn{2}{|c|}{ Father } & \multicolumn{2}{|c|}{ Mother } \\
\hline & $f$ & $\%$ & $f$ & $\%$ \\
\hline Farmer & 8 & 8.00 & 3 & 3.00 \\
\hline Businessman & 8 & 8.00 & 4 & 4.00 \\
\hline Sari-sari Store Owner & 1 & 1.00 & 17 & 17.00 \\
\hline Driver & 36 & 36.00 & 0 & 0.00 \\
\hline Teacher & 1 & 1.00 & 1 & 1.00 \\
\hline Barangay Official & 1 & 1.00 & 2 & 2.00 \\
\hline Laborer & 19 & 19.00 & 10 & 10.00 \\
\hline Carpenter & 8 & 8.00 & 0 & 0.00 \\
\hline Engineer & 2 & 2.00 & 0 & 0.00 \\
\hline Fisherman & 3 & 3.00 & 3 & 3.00 \\
\hline Security Guard & 2 & 2.00 & 0 & 0.00 \\
\hline Vendor & 1 & 1.00 & 0 & 0.00 \\
\hline Welder & 1 & 1.00 & 0 & 0.00 \\
\hline Private Firm Employee & 0 & 0.00 & 2 & 2.00 \\
\hline Technician & 0 & 0.00 & 1 & 1.00 \\
\hline Housemaid & 0 & 0.00 & 3 & 3.00 \\
\hline Housekeeper & 1 & 1.00 & 26 & 26.00 \\
\hline Not Stated & 8 & 8.00 & 28 & 28.00 \\
\hline Total & 100 & 100.00 & 100 & 100.00 \\
\hline
\end{tabular}

The foregoing data suggested that the parents of the student-respondents were gainfully engaged in an activity that served as the main source of their family income. Usually, the father were the ones engaged in gainful activities while the mothers served as the support system being the ones who took good care of the needs of the family members.

\subsubsection{Number of Days of Attendance in School}

Table 5 presents the number of days of attendance of the student-respondents during the first and second quarters.

The table shows that the Mean Number of Days of Attendance of student-respondents during the first and second quarters was posted at 50 days and 52 days, respectively, with SD of 2.44 days and 2.32 days.

The overall mean number of days of attendance of student-respondents was calculated at 51 days with a SD of 2.38 days. The data suggested that the student-respondents regularly attended their schooling. They maximized their attendance in school and seldom incurred absences, only during important personal and family events.

Table 5: Number of Days of Attendance in School of Student-Respondents

\begin{tabular}{c|c|c}
\hline \hline Quarter & Mean & SD \\
\hline First & 50 days & 2.44 days \\
Second & 52 days & 2.32 days \\
\hline Overall & $\mathbf{5 1}$ days & $\mathbf{2 . 3 8}$ days \\
\hline \hline
\end{tabular}




\subsubsection{Attitude Toward Reading}

Table 6 appraises the attitude of the student-respondents toward reading. There were 10 attitude statements considered whereby the student-respondents agreed or disagreed with each statement.

The table shows that the student-respondents "agreed" on all the statements depicting their attitude toward reading with weighted means ranging from 4.18 to 4.32 . Two attitude statements equally obtained the highest weighted mean. These corresponded to the following: "reading facilitates my studies learning" and "I desire to be a good reader." On the other hand, the statement stating, "I am enthusiastic in reading books and magazines or journals" obtained the least weighted mean.

Table 6: Attitude Toward Reading of Student-Respondents

\begin{tabular}{l|cc}
\hline \hline \multicolumn{1}{c|}{ Statement } & $\begin{array}{c}\text { Weighted } \\
\text { Mean }\end{array}$ & Interpre-tation \\
\hline 1. I am interested in reading. & 4.30 & $\mathrm{~A}$ \\
2. I believe reading can make my studies easier. & 4.25 & $\mathrm{~A}$ \\
3. I am enthusiastic in reading books and magazines or journals. & 4.18 & $\mathrm{~A}$ \\
4. I like exploring things through Reading. & 4.29 & $\mathrm{~A}$ \\
5. Reading facilitates my studies learning. & 4.32 & $\mathrm{~A}$ \\
6. Eventually, reading improves my academic performance. & 4.29 & $\mathrm{~A}$ \\
7. I can learn many things through reading. & 4.28 & $\mathrm{~A}$ \\
8. I feel more fulfilled by being proficient in reading. & 4.20 & $\mathrm{~A}$ \\
9. I desire to be a good reader. & 4.32 & $\mathrm{~A}$ \\
10. Reading allows me to be innovative and makes me more output-oriented. & 4.29 & $\mathrm{~A}$ \\
\hline Grand Weighted Mean & Interpretation & $\mathbf{4 . 2 7}$ \\
\hline \hline
\end{tabular}

Legend: 4.51-5.00 Strongly Agree (SA)

$\begin{array}{lll}3.51-4.50 & \text { Agree } & \text { (A) } \\ 2.51-3.50 & \text { Uncertain } & \text { (U) } \\ 1.51-2.50 & \text { Disagree } & \text { (D) } \\ 1.00-1.50 & \text { Strongly Disagree } & \text { (SD) }\end{array}$

Taken as a whole, the student-respondents "agreed" their attitude toward reading being manifested by the grand weighted mean of 4.27. This indicated that the student-respondent manifested a favourable attitude toward reading, which signified that they were interested in it.

\subsection{Level of Reading Proficiency of Student-Respondents Based on the Phil-IRI Results}

Table 7 discloses the level of reading proficiency of student-respondents based on the Phil-IRI results.

Table 7: Level of Reading Proficiency of Student-Respondents Based on the Phil-IRI Results

\begin{tabular}{c|c|c}
\hline \hline Level & $\mathbf{f}$ & \% \\
\hline Independent & 21 & 21.00 \\
Instructional & 45 & 45.00 \\
Frustration & 34 & 34.00 \\
\hline Total & $\mathbf{1 0 0}$ & $\mathbf{1 0 0 . 0 0}$ \\
\hline \hline
\end{tabular}

From the table, it can be noted that a number of the student-respondents, that is, 45 or 45.00 percent were rated as "instructional" while 34 or 34.00 percent of them were assessed as in the "frustration" level and the remaining 21 or 21.00 percent were "independent."

The foregoing data signified that the student-respondents still need to enhance their reading skills and abilities to be independent readers. Thus, an intervention should be proposed for implementation. 


\subsection{Comparison of the Reading Proficiency Level of the Student-Respondents When Grouped According to Their Profile Variates}

Table 8 reflects the comparison of the reading proficiency level of the student-respondents when grouped according to their profile variates, namely: age, sex, nutritional status, parents' highest educational attainment, parents' occupation, number of days of attendance in school, and attitude toward reading.

\subsubsection{Age}

In the comparison of the reading proficiency level of the student-respondents when grouped according to their age with the use of the One-Way Analysis of Variance (ANOVA), the computed F-value was posted at 1.634 at $\mathrm{df}=2$ and 91 and $\alpha=.05$ with a $p$-value of 0.201 ; the critical value was set at 3.070. The computed value was compared with the critical value and the $p$-value was compared with the $\alpha$.

Table 8: Comparison of the Reading Proficiency Level of the Student-Respondents When Grouped According to Their Profile Variates

\begin{tabular}{|c|c|c|c|c|c|}
\hline \multirow[b]{2}{*}{ Variate } & \multicolumn{2}{|c|}{ F-Value } & \multirow[b]{2}{*}{ df } & \multirow{2}{*}{$\begin{array}{l}\text { p-Value } \\
@ \alpha=.05\end{array}$} & \multirow{2}{*}{$\begin{array}{l}\text { Evaluation/ } \\
\text { Decision }\end{array}$} \\
\hline & Computed & Critical & & & \\
\hline Age & 1.634 & 3.070 & $\begin{array}{c}2 \\
91 \\
\end{array}$ & 0.201 & NS / Accept Ho \\
\hline Sex & 3.190 & 3.070 & $\begin{array}{c}2 \\
90 \\
\end{array}$ & 0.046 & S / Reject Ho \\
\hline Nutritional Status & 0.180 & 3.070 & $\begin{array}{c}2 \\
91\end{array}$ & 0.835 & NS / Accept Ho \\
\hline $\begin{array}{l}\text { Parents' Highest Educational } \\
\text { Attainment }\end{array}$ & 3.166 & 3.070 & $\begin{array}{c}2 \\
97\end{array}$ & 0.047 & S / Reject Ho \\
\hline Parents' Occupation & 7.017 & 3.070 & $\begin{array}{c}2 \\
97\end{array}$ & 0.001 & S / Reject Ho \\
\hline $\begin{array}{l}\text { Number of Days of } \\
\text { Attendance in School }\end{array}$ & 3.078 & 3.070 & $\begin{array}{c}2 \\
97\end{array}$ & 0.050 & S / Reject Ho \\
\hline Attitude Toward Reading & 2.216 & 3.070 & $\begin{array}{c}2 \\
96\end{array}$ & 0.110 & NS / Accept Ho \\
\hline
\end{tabular}

$\mathrm{S}=$ Significant NS = Not Significant

The result of the comparison showed that the computed value turned lesser than the critical value and the $p$-value turned greater than the $\alpha$. This signified that the noted disparities were not significant. Thus, the null hypothesis stating, "there are no significant differences among the reading proficiency level of the student-respondents when grouped according to their age," was accepted. This denoted that the reading proficiency level of the student-respondents, when grouped according to their age, was essentially similar, which indicated that irrespective of the age differences among the students, their reading level was similar.

\subsubsection{Sex}

In the comparison of the reading proficiency level of the student-respondents when grouped according to their sex with the use of ANOVA, the computed F-value was posted at 3.190 at $\mathrm{df}=2$ and 90 and $\alpha=.05$ with a $p$-value of 0.046 ; the critical value of 3.070. The computed value was compared with the critical value and the $p$-value was compared with the $\alpha$

The result of the comparison showed that the computed value turned greater than the critical value and the $p$-value turned lesser than the $\alpha$, this signified that the noted disparities were significant, thus, the null hypothesis stating, "there are no significant differences among the reading proficiency level of the student-respondents when grouped according to their sex," was rejected. This denoted that the reading proficiency level of the student-respondents, when grouped according to their sex, significantly differed, which indicated that the reading level of the female students differed from that of their male counterpart. From the means, it can be noted that the female students manifested higher reading level than the male students. 


\subsubsection{Nutritional Status}

In the comparison of the reading proficiency level of the student-respondents when grouped according to their nutritional status with the use of ANOVA, the computed F-value was posted at 0.180 at $\mathrm{df}=2$ and 91 and $\alpha=.05$ with a p-value of 0.835 ; the critical value was set at 3.070. The computed value was compared with the critical value and the p-value was compared with the $\alpha$.

The result of the comparison showed that the computed value turned lesser than the critical value and the $p$-value turned greater than the $\alpha$, this signified that the noted disparities were not significant, thus, the null hypothesis stating, "there are no significant differences among the reading proficiency level of the student-respondents when grouped according to their nutritional status," was accepted. This denoted that the reading proficiency level of the student-respondents, when grouped according to their nutritional status was essentially similar, which indicated that irrespective of the nutritional status differences among the students, their reading level was still similar.

\subsubsection{Parents' Highest Educational Attainment}

In the comparison of the reading proficiency level of the student-respondents when grouped according to their parents' highest educational attainment with the use of ANOVA, the computed F-value was posted at 3.166 at $\mathrm{df}=2$ and 97 and $\alpha=.05$ with a $p$-value of 0.047 ; the critical value of 3.070 . The computed value was compared with the critical value and the $p$-value was compared with the $\alpha$.

The result of the comparison showed that the computed value turned greater than the critical value and the $\mathrm{p}$-value turned lesser than the $\alpha$, this signified that the noted disparities were significant, thus, the null hypothesis stating, "there are no significant differences among the reading proficiency level of the student-respondents when grouped according to their parents' highest educational attainment," was rejected. This denoted that the reading proficiency level of the student-respondents when grouped according to their parents' highest educational attainment, significantly differed, which indicated that the reading level of the students whose parents had higher educational attainment differed from those students whose parents had attained lower educational level.

\subsubsection{Parents' Occupation}

In the comparison of the reading proficiency level of the student-respondents when grouped according to their parents' occupation with the use of ANOVA, the computed F-value was posted at 7.017 at $\mathrm{df}=2$ and 97 and $\alpha=.05$ with a $p$-value of 0.001 ; the critical value of 3.070 . The computed value was compared with the critical value and the p-value was compared with the $\alpha$.

The result of the comparison showed that the computed value turned greater than the critical value and the $\mathrm{p}$-value turned lesser than the $\alpha$, this signified that the noted disparities were significant, thus, the null hypothesis stating, "there are no significant differences among the reading proficiency level of the student-respondents when grouped according to their parents' occupation," was rejected. This denoted that the reading proficiency level of the student-respondents when grouped according to their parents' occupation, significantly differed, which indicated that the reading level of the students whose parents had stable gainful occupations differed from those students whose parents had irregular occupations. This could be attributed to the fact that parents with stable gainful occupations earned regular income, which assured them that they could pursue their schooling.

\subsubsection{Number of Days of Attendance in School}

In the comparison of the reading proficiency level of the student-respondents when grouped according to their number of days of attendance in school with the use of ANOVA, the computed F-value was posted at 3.078 at $\mathrm{df}=2$ and 97 and $\alpha=.05$ with a $p$-value of 0.050 ; the critical value of 3.070 . The computed value was compared with the critical value and the $p$-value was compared with the $\alpha$.

The result of the comparison showed that the computed value turned greater than the critical value and the $p$-value turned equal to the $\alpha$, this signified that the noted disparities were significant, thus, the null hypothesis stating, "there are no significant differences among the reading proficiency level of the student-respondents when grouped according to their number of days of attendance in school," was rejected. This denoted that the reading proficiency level of the student-respondents, when grouped according to their number of days of attendance in school, significantly differed, which indicated that the students whose attendance in school was maximized showed higher reading levels than the truant students. 


\subsubsection{Attitude Toward Reading}

In the comparison of the reading proficiency level of the student-respondents when grouped according to their attitude toward reading with the use of ANOVA, the computed F-value was posted at 2.216 at $\mathrm{df}=2$ and 96 and $\alpha=.05$ with a $p$-value of 0.110 ; the critical value was set at 3.070. The computed value was compared with the critical value and the p-value was compared with the $\alpha$.

The result of the comparison showed that the computed value turned lesser than the critical value and the $p$-value turned greater than the $\alpha$. This signified that the noted disparities were not significant. Thus, the null hypothesis stating, "there are no significant differences among the reading proficiency level of the student-respondents when grouped according to their attitude toward reading," was accepted. This denoted that the reading proficiency level of the student-respondents when grouped according to their attitude toward reading was essentially similar, which indicated that irrespective of the attitude of the students in reading, their reading level was still similar.

In summary, the reading level of the student-respondents differed in terms of sex, parents' highest educational attainment, parents' occupation and the number of days of attendance in school, but similar along with age, nutritional status, and attitude toward reading.

\subsection{Academic Performance of Student-Respondents in Reading}

Table 9 presents the academic performance of student-respondents in reading during the first and second quarters.

From the said table, it can be noted that the mean academic performance of the student-respondents was: during the first quarter, 85.04 with a SD of 6.23 , while during the second quarter, 86.11 with a SD of 5.86. The overall mean academic performance of the student-respondents was posted at 85.58 with a SD of 6.04 .

Table 9: Academic Performance of Student-Respondents in Reading

\begin{tabular}{c|c|c}
\hline \hline Quarter & Mean & SD \\
\hline First & 85.04 & 6.23 \\
Second & 86.11 & 5.86 \\
\hline Overall & $\mathbf{8 5 . 5 8}$ & $\mathbf{6 . 0 4}$ \\
\hline \hline
\end{tabular}

The data signified that the student-respondents manifested a favourable academic performance in reading which indicated that their reading level tends to be high.

3.5 Relationship Between the Academic Performance of the Student-Respondents and their Reading Proficiency Level Table 10 contains the relationship between the academic performance of the student-respondents and their reading proficiency level.

Table 10: Relationship Between the Academic Performance of the Student-Respondents and their Reading Proficiency Level

\begin{tabular}{c|c|c|c|c}
\hline \hline \multicolumn{2}{c|}{ Linear Association } & $\begin{array}{c}\text { Fisher's t- } \\
\text { Value }\end{array}$ & p-Value & Evaluation/Decision \\
\hline Coefficient & Degree & 2.031 & 0.050 & Significant / Reject Ho \\
\hline 0.201 & Weak & 2010 \\
\hline
\end{tabular}

Fisher's t-Critical Value $= \pm 1.984$

$\mathrm{df}=98 \alpha=.05$

In associating the relationship between the academic performance of the student-respondents and their reading proficiency level using the Pearson Product-Moment Coefficient of Correlation or Pearson's r, the coefficient of linear association was posted at 0.201 , denoting a "weak" linear association. To ascertain the significance of the noted coefficient, the Fisher's t-Test was utilized as a posteriori test. Corrolarily, the computed value was posted at 2.031 at $\mathrm{df}=98$ and $\alpha=.05$ with a $p$-value of 0.050 ; the critical value was set at \pm 1.984 . The computed value was compared with the critical value and the $p$-value was compared with the $\alpha$. 
The result of the comparison showed that the computed value turned greater than the critical value and the $p$-value turned equal to the $\alpha$, this signified that the noted linear association was significant, thus, the null hypothesis stating, "there is no significant relationship between the academic performance of the student-respondents and their reading proficiency level," was rejected. This denoted that the academic performance of the student-respondents was significantly influenced by their reading proficiency level. The positive coefficient suggested a direct proportional linear relationship indicating that the students with higher reading proficiency levels manifested higher academic performance than those whose reading performance was on the average only.

\section{Conclusions}

The study determined the reading proficiency of the Grade 3 students in the District of Catbalogan VI, Schools Division of Catbalogan City, and its influence on their academic performance during the School Year 2019-2020. The study's data signified that the student-respondents were on their right age fitted for the grade level they were enrolled in, whereby female dominance existed among them, indicating that more of this sex group were in school and participated in the field interview at the time of visit. The student-respondents were in their best health, which suggested that they understood and learned their lessons. Their parents were functionally literate; that is, they had the ability to read, write, and understand the simple message, and that they were apt to receive information disseminated through the tri-media. Also, the parents of the student-respondents were gainfully engaged in an activity that served as the main source of their family income. Usually, the fathers were the ones engaged in gainful activities while the mothers served as the support system, being the ones who took good care of the needs of the family members. The student-respondents regularly attended their schooling, maximized their attendance in school, and seldom incurred absences, only during important personal and family events. Lastly, the data revealed that they manifested a favourable attitude toward reading which signified that they were interested in it.

However, the student-respondents still need enhancement in their reading skills and abilities toward being independent readers. Thus, an intervention scheme could be proposed for implementation. The student-respondents' reading proficiency level differed in terms of sex, parents' highest educational attainment, parents' occupation, and the number of days of attendance in school, but similar along with age, nutritional status, and attitude toward reading. They manifested a favourable academic performance in reading which indicated that their reading proficiency level tended to be high as it was shown that the former was significantly influenced by the latter. The positive coefficient suggested a direct proportional linear relationship indicating that the students with higher reading proficiency levels manifested higher academic performance than those whose reading performance was on the average only.

In as much as female students were proven to manifest higher reading proficiency levels, teachers should provide reading enhancement activities for male students to be at par with their female counterparts. Also, it is encouraged that parents, particularly those with higher educational attainment and whose occupations are permanent and high earning, should assist their children with their reading skills and habits and provide them with reading materials. They could motivate their children to set a regular daily reading schedule and ensure that their children attend classes regularly to enhance their reading prowess. Finally, as mentioned earlier, a reading intervention program may be proposed and implemented to enhance the students' reading skills.

\section{References}

[1] Aquino, G. V. (2000). Principles and Methods of Effective Teaching. Manila: National Bookstore, Inc.

[2] Cabardo, J. R. O. (2016). Reading Proficiency Level of Students: Basis For Reading Intervention Program. Hagonoy National High School/Southeastern College of Padada, Inc.

[3] Koda, K., \& Zehler, A. M. (Eds.). (2008). Learning to read across languages: Cross-Linguistic relationships in first-and second-language literacy development. London: Routledge.

[4] Leipzig, D. H. (2001). What Is Reading? Reading Rockets. https://www.readingrockets.org/article/what-reading

[5] OECD Programme for International Student Assessment (PISA). (2018). https://www.oecd.org/pisa/publications/pisa-2018-results.html

[6] The National Academies Press. (2010). Challenges and Opportunities for Education about Dual Use Issues in the Life Sciences. https://www.interacademies.org/publication/challenges-and-opportunities-education-about-dual-use-issues-life-sciences 